\title{
سلطة القاضي الجنائي في تقدير الخبرة
}

\author{
د إخروفة غانية \\ كلبة الحقوق \\ جامعة الإخوة منتوري قسنطينة

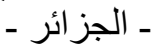

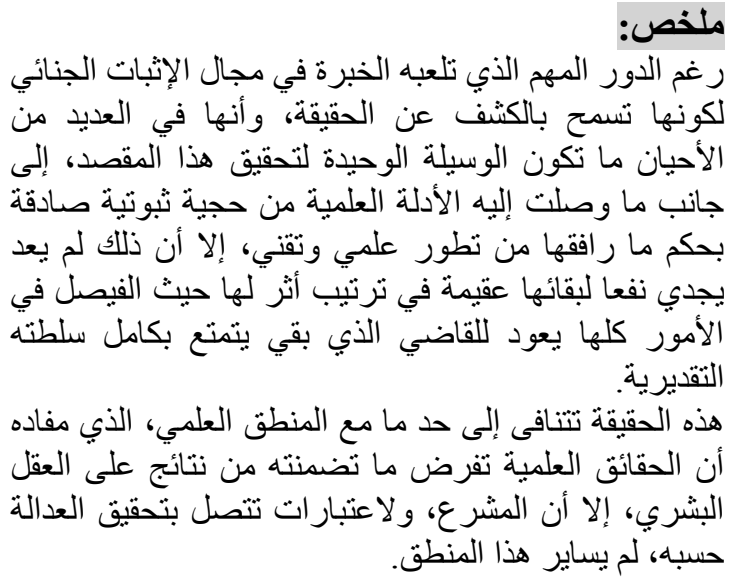

انكب العديد من الباحثين

Despite the important role played by the expert report in the field of criminal identification, since it reveals the truth and is considered, in most cases, as the only way to achieve this goal; besides the authentic scientific evidence that accompanies it as a scientific and technical development, these contributions have no more use, however. As they have remained unproductive and without any effect. Since the entire decision dependson the judge who remains the only one to enjoy total estimated authority.

This reality contradicts to a certain extent the scientific logic which holds that scientific truths impose their results on the human mind. Nevertheless, the legislator, and for considerations relating to the realization of the justice according to him, does not adapt to this logic. 


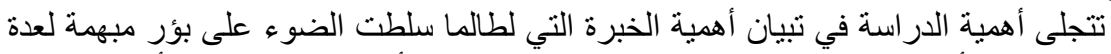

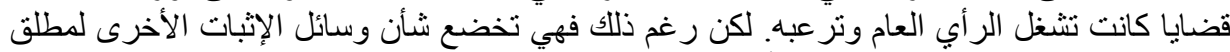

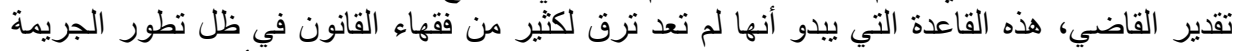

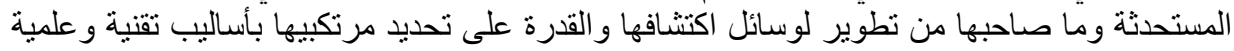

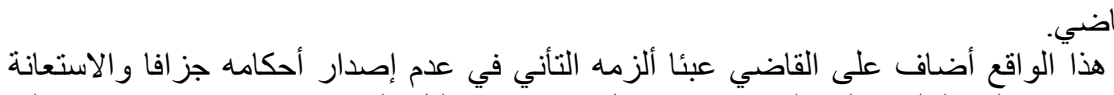

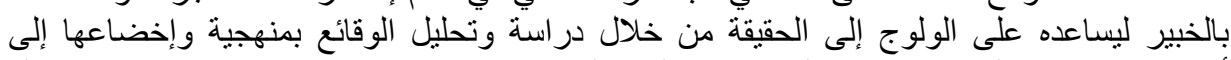

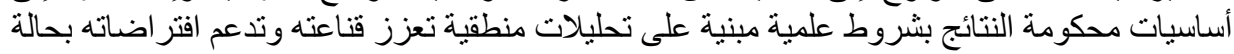

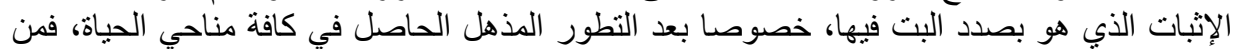

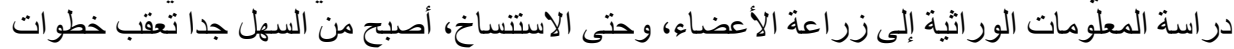

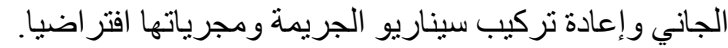

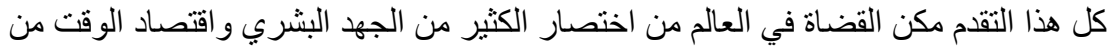

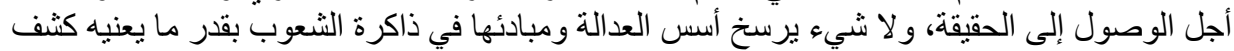

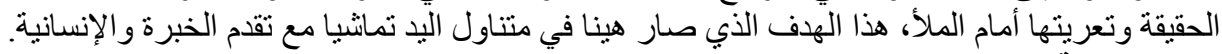

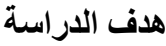

تهدف هذه الدراسة إلى تبيان حجية تقرير الخبرة بإيراد مختلف الآراء الفقهية والقضائية

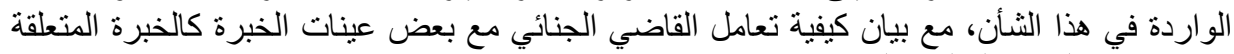
بالإجهاض والخبرة العقلية والنفسية.

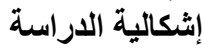

نظر الما تمتاز به الخبرة من خصوصية، فهل ستعامل وعلى قدم المساو اة مع الأدلة الأخرى

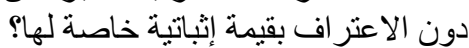

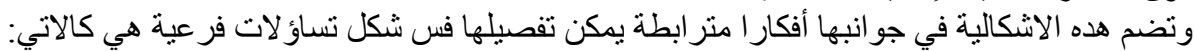

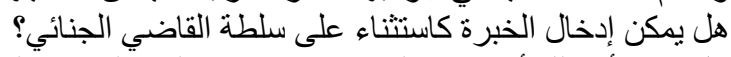
هل من شأن ذلك أن يؤدي إلى تضييق نطاق سلطة القاضي التقديرية؟

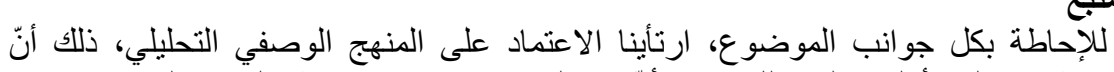

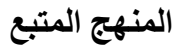

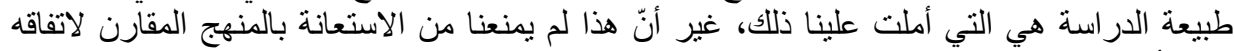

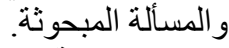

مر اعاة لكل ما تقدم، حاولنا تقسيم عملنا هذا وفق خطة ارتائنا أنها تخدم الموضوع، فقسمنا تقسيم الدراسة

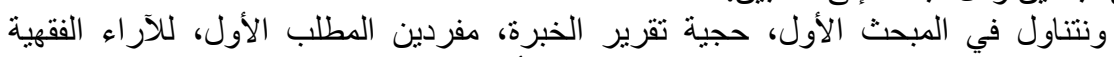

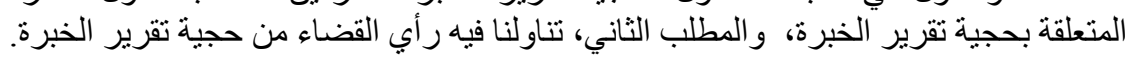

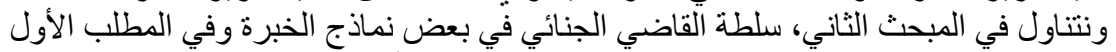

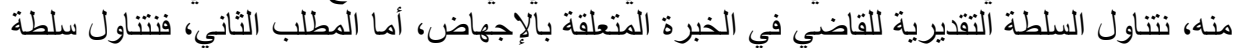
ذات القاضي في تقدير الخبرة العقلية والنفسية.

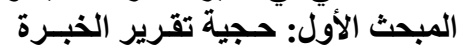

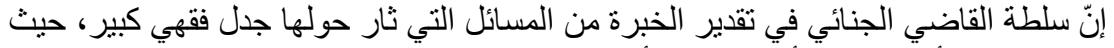

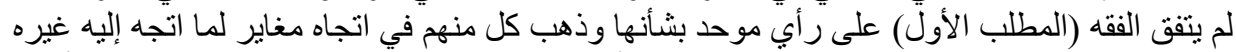

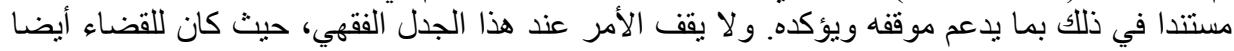
نصيب منه (المطلب الثاني). 
المطلب الأول: الآراء الفقهية المتعلقة بحجية تقرير الخبرة

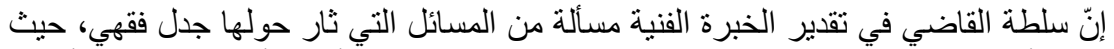

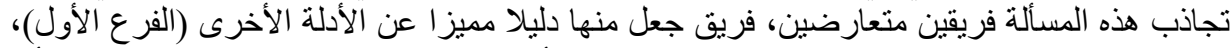

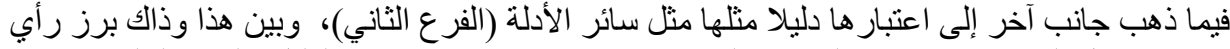

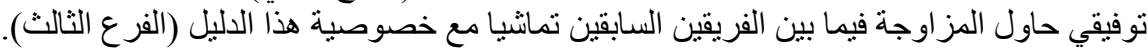

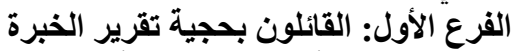

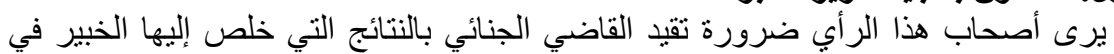

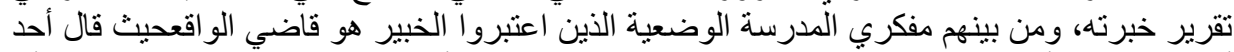

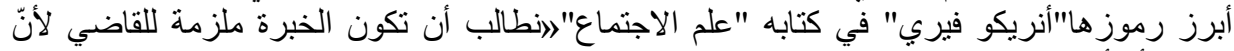

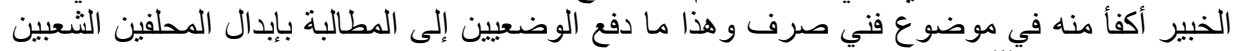
بالمحلفين العلماءه| (1). يتفق هذا التوجه مع ما ذهب اليه الدكتور "محمد محي الدين عوض" الدئ، الذي اعتبر أنّ الدليل

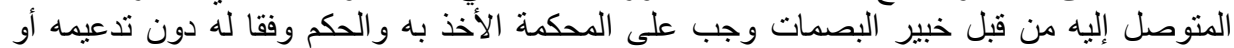
مساندته بأدلة أخرى (2).

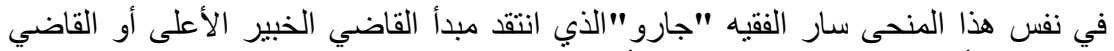

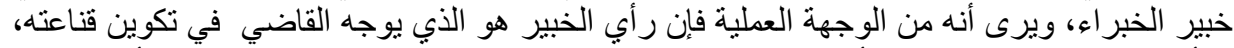

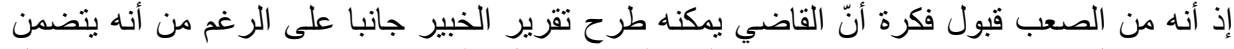

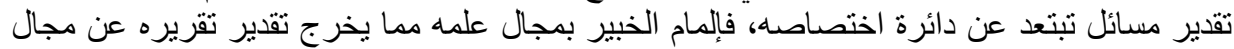

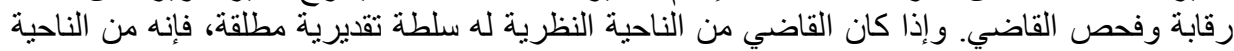

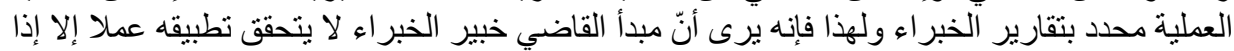

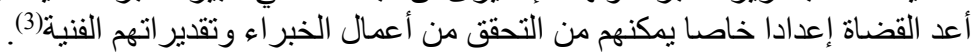

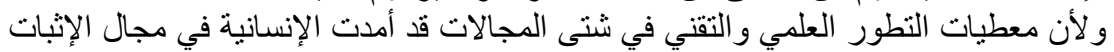

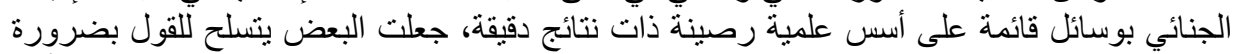

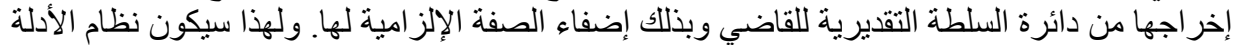

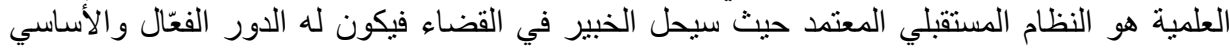

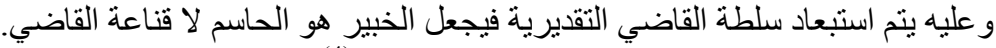

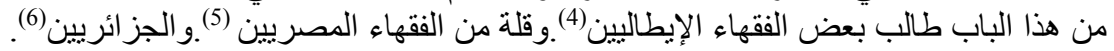

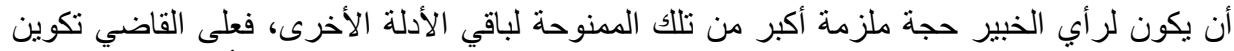

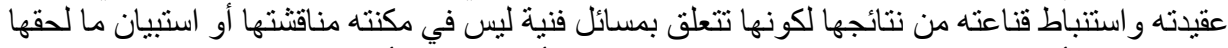

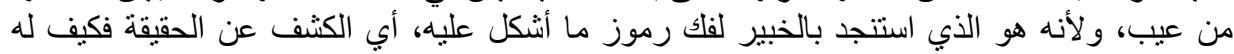

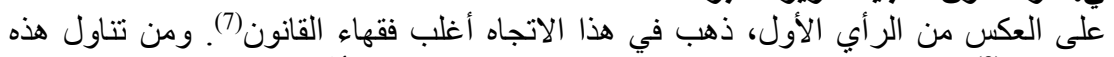

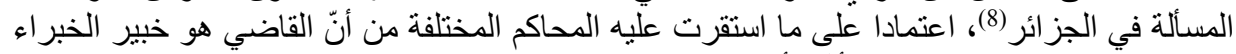

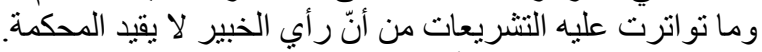

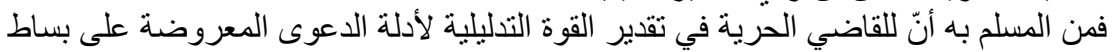

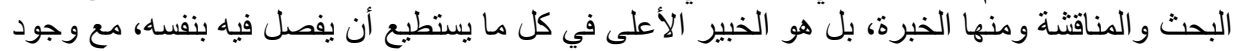

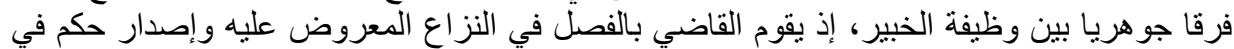

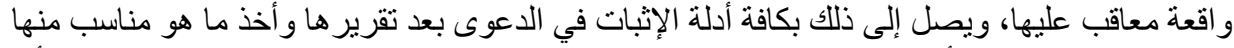

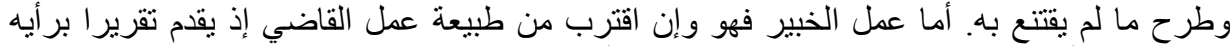

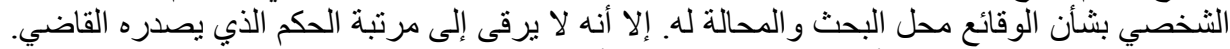
فهو عبارة عن استثارة فنية يأخذ بها القاضي إذا الطمأن إليها ويستبعده إذا لم يقتنع به. 


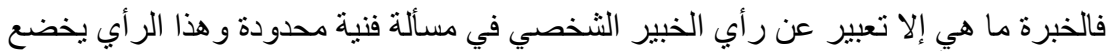

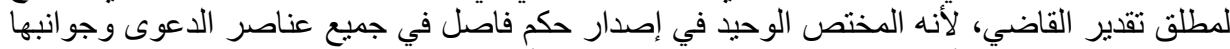

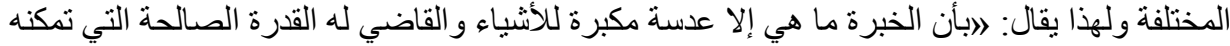

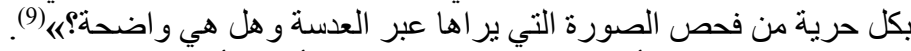

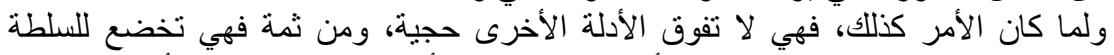

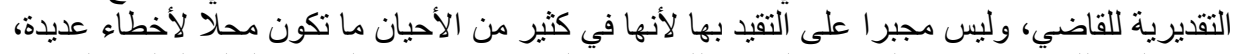

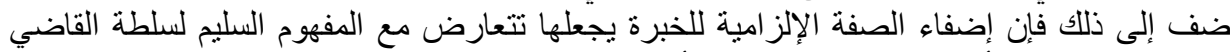

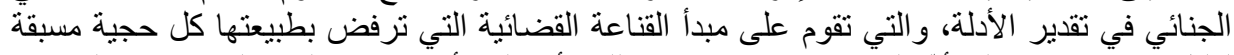

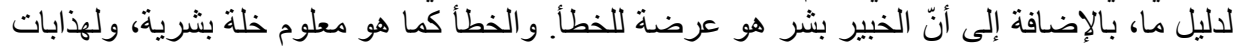

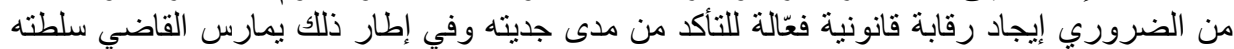

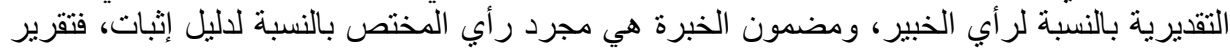
الخبير يوضح بيان هذا الدليل وتفصيل عناصره ثم يبين وجهة نظره الفي الفنية إزاء ما يمكن أن يكون له من

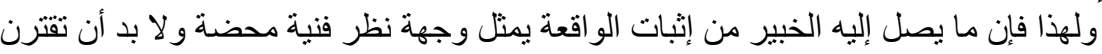

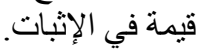

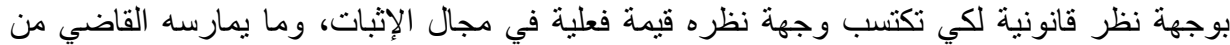

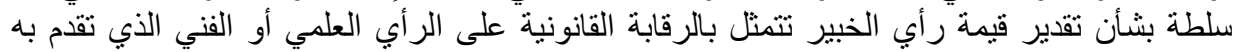

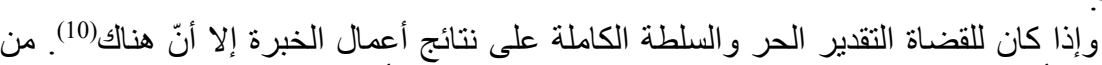

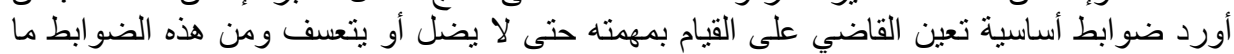

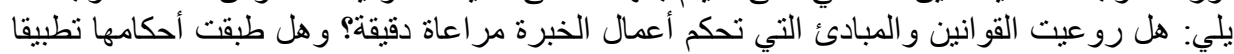

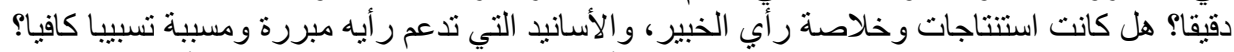

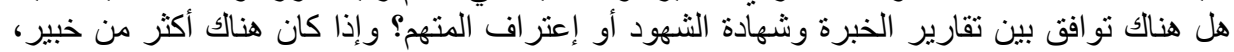

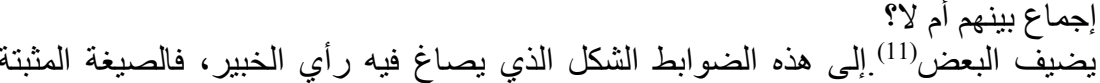

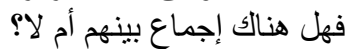

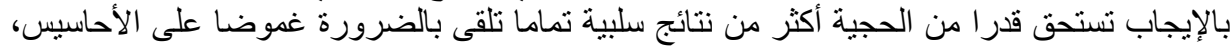

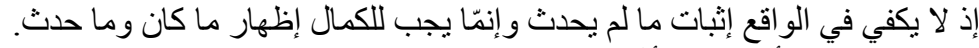

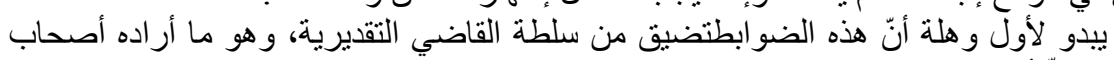

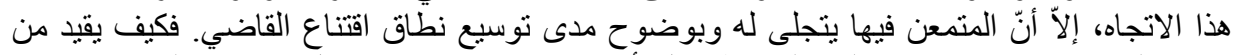

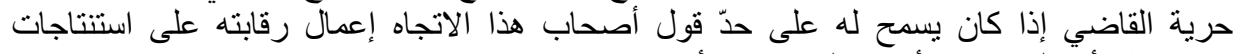
وخلاصة رأي الخبير، و الأسانيد التي تدعم رأيه فيما إذا كانت مبررة إن ومسببة تسبيبا كافيا.

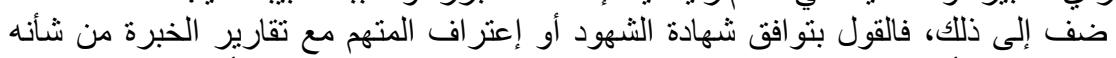

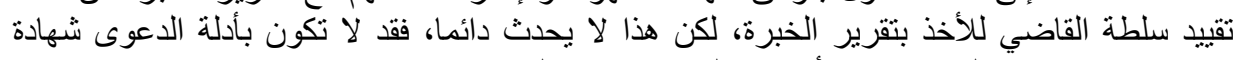

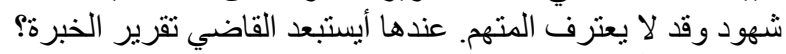

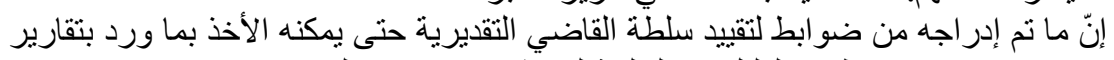

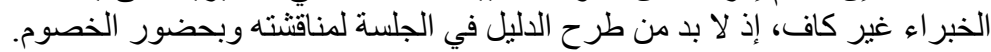

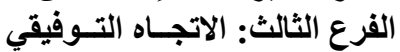

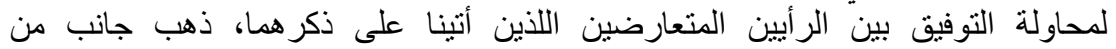

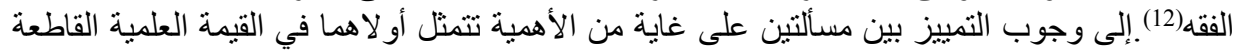

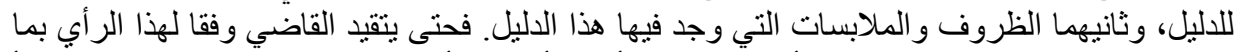

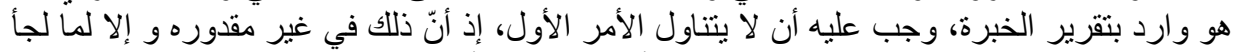

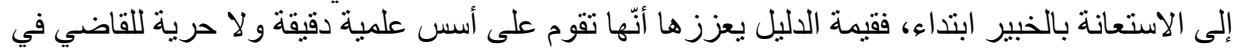
مناقشتها كونها تشكل حقائق علمية ثابتة. 


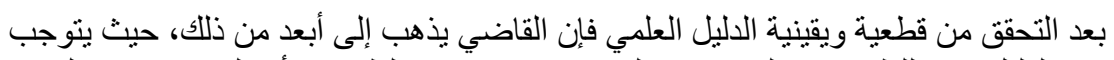

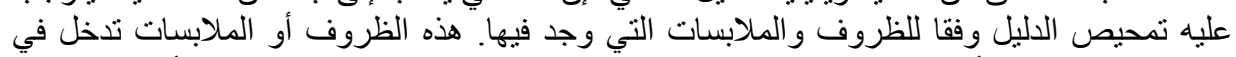

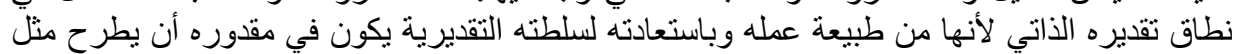

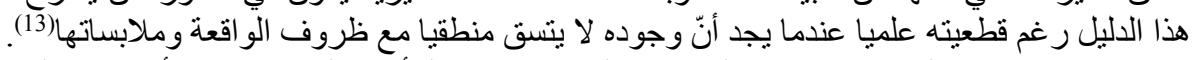

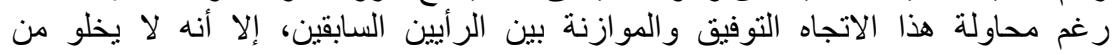

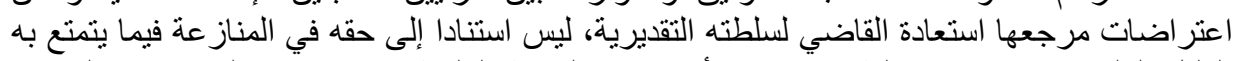

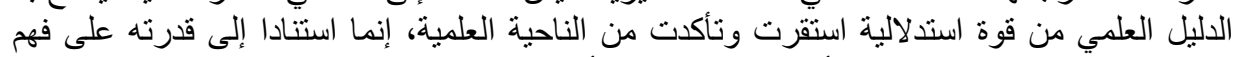

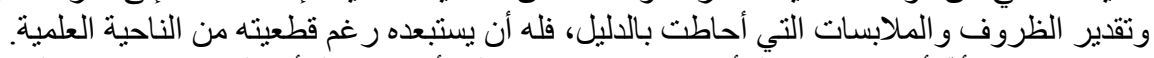

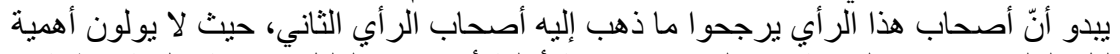

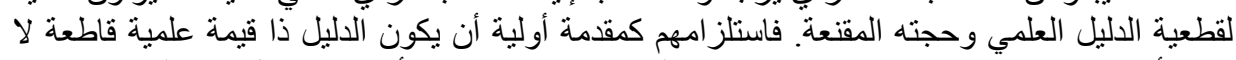

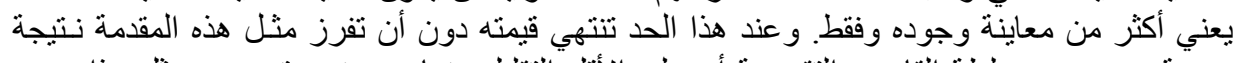

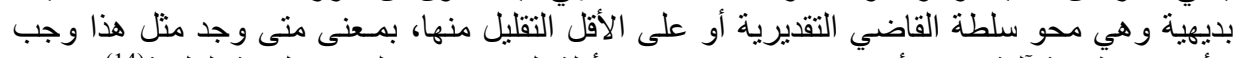

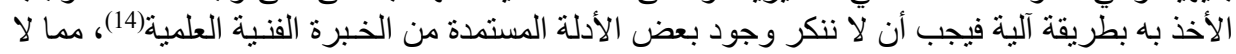

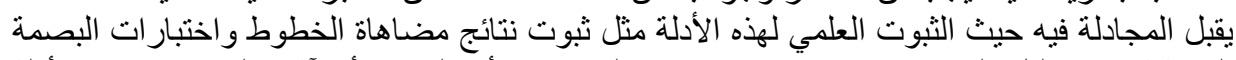

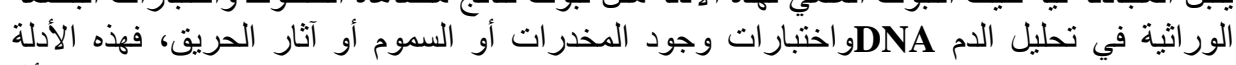

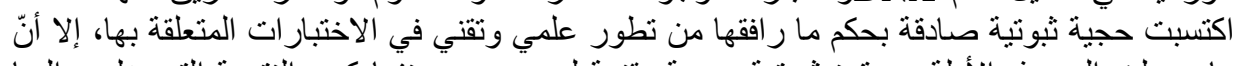

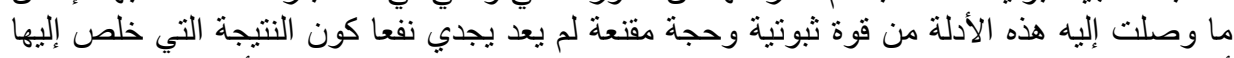

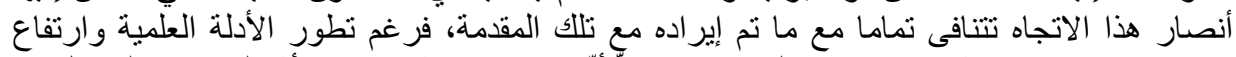

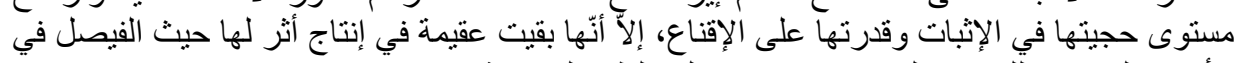

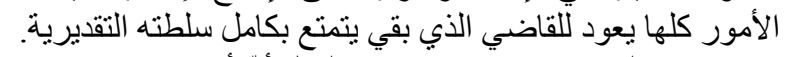

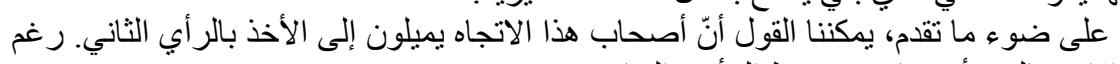

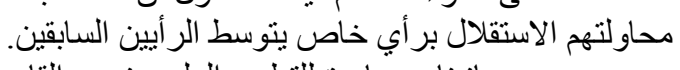

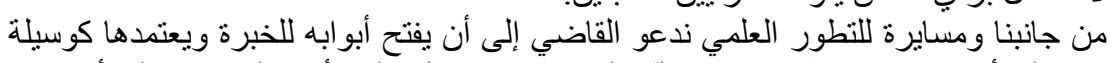

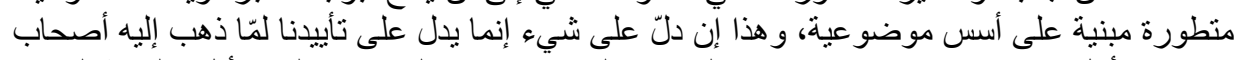

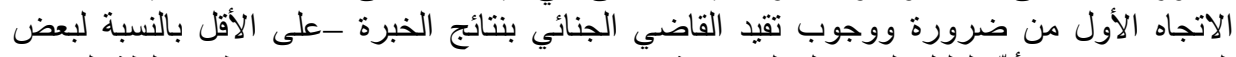

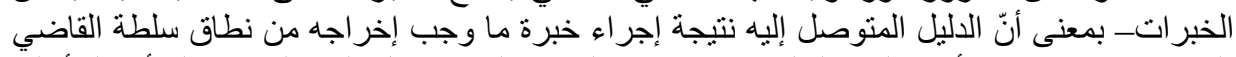

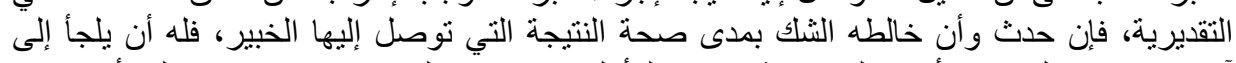

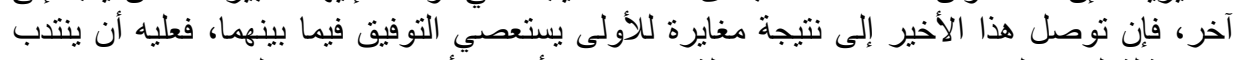

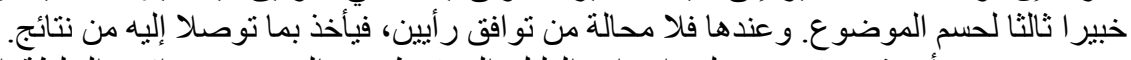

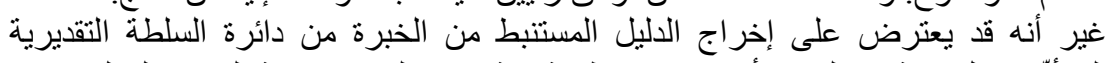

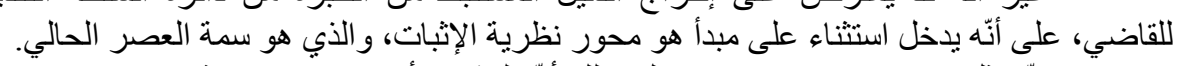

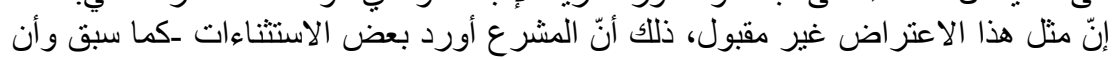

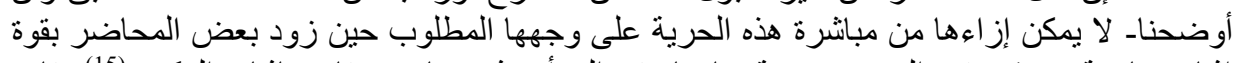

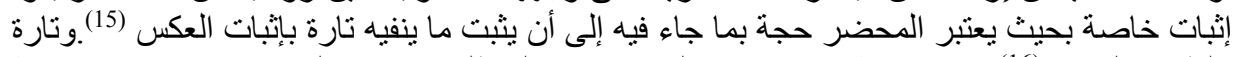

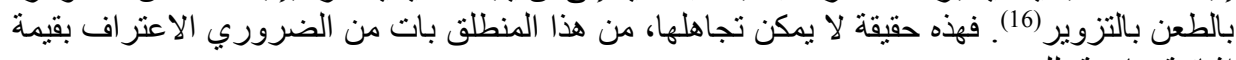

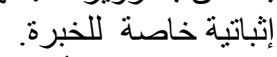

المطلب الثاني: رأي القضاء من حجية تقرير الخبرة

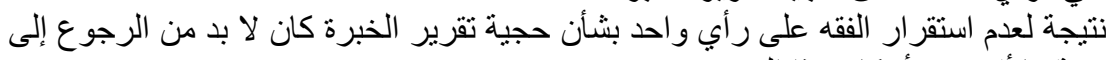

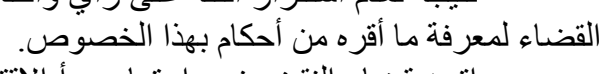

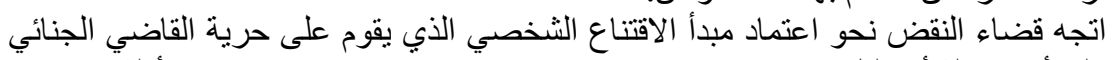

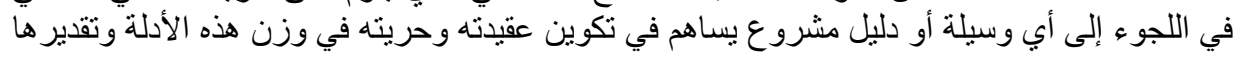


حق قدرها، دونما إعطاء أي دليل قوة إثباتية أكثر من غيره من الأدلة بمقتضى ما أقرّه من أحكام، تاركا

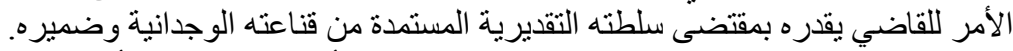

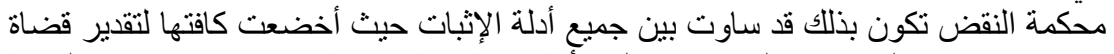

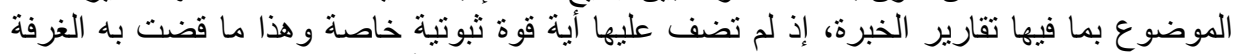

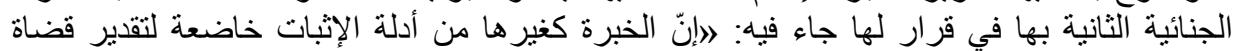

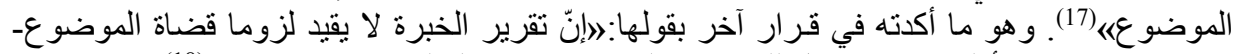

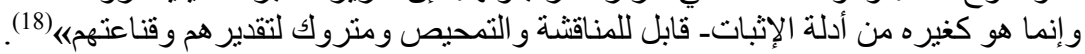

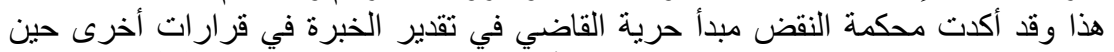

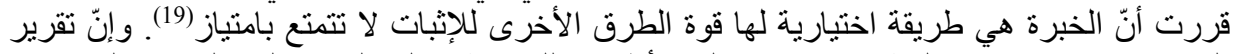

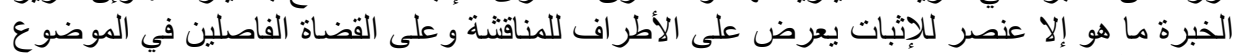

فمن المستقر عليه قضاء أن تقبير تقرير الخبرة برجع في الحقبقة إلى طبيعة المسألة الفنبة لتقديره(20).

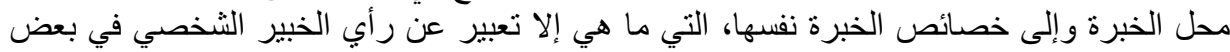

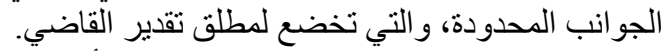

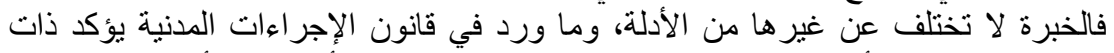

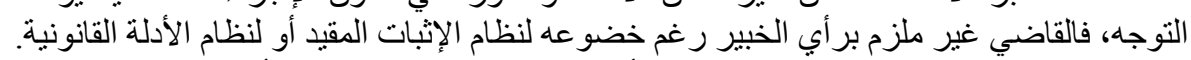

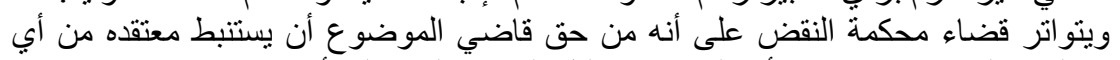

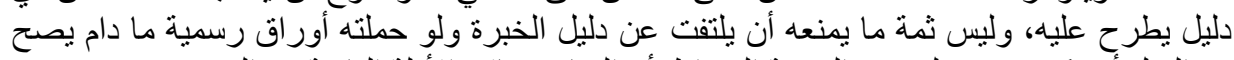

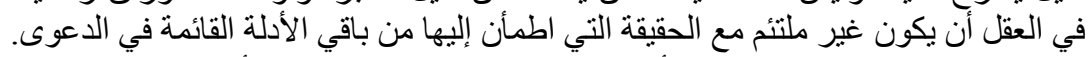

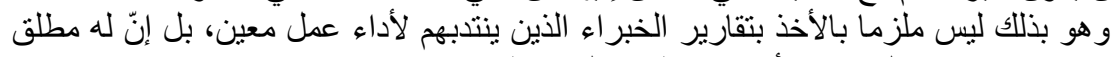

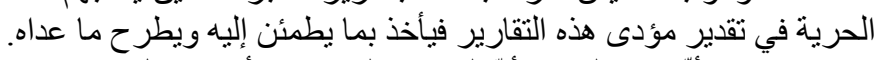

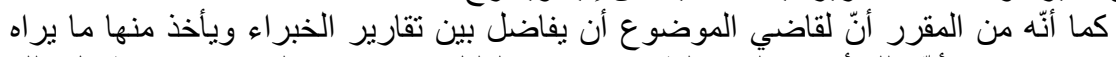

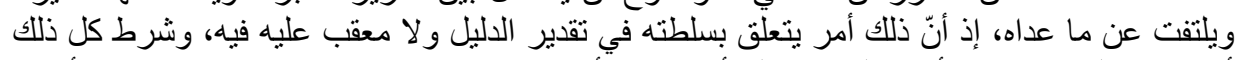

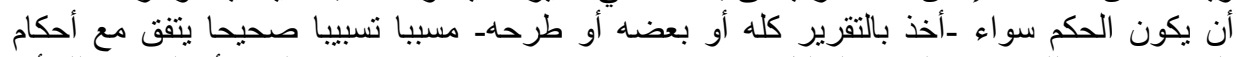

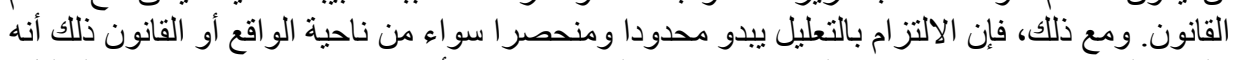

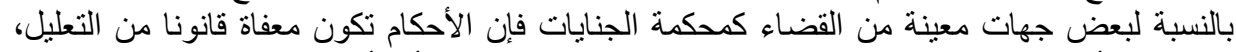

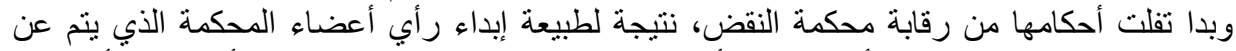

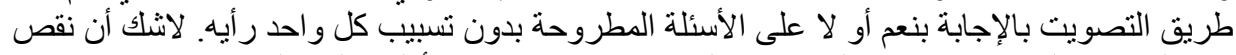

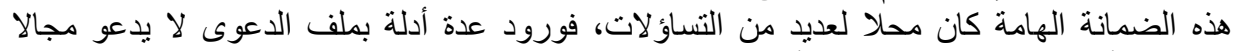

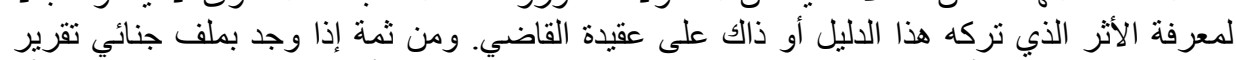

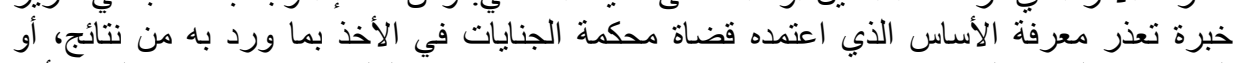

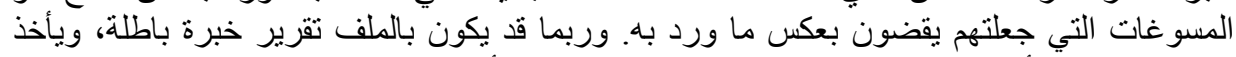

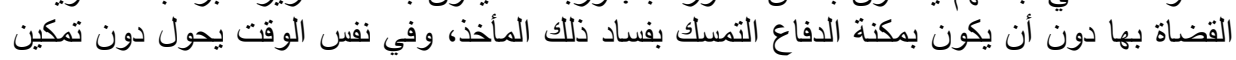

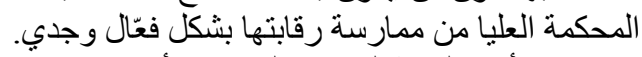

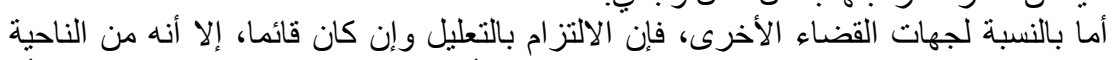

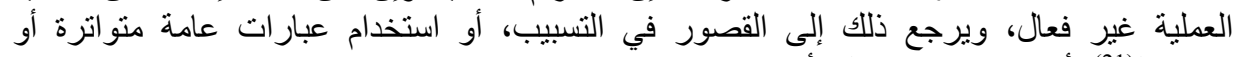
متناقضة(21)، أو بسبب عدم يقينية الأسباب.

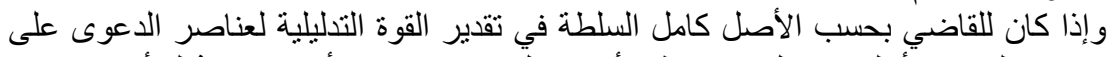

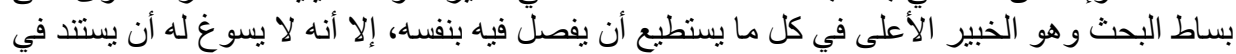

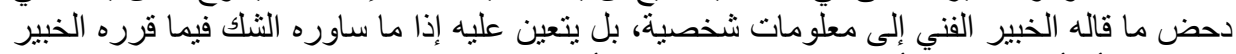

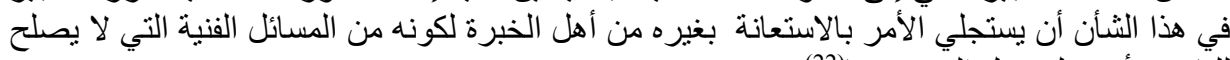
للقاضي أن بحل محل الخبير فيهان الخدان. 
المبحث الثاني: سلطة القاضي الجنائي في بعض نماذج الخبرة

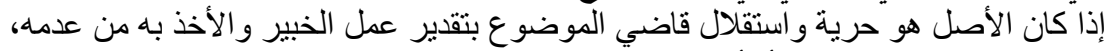

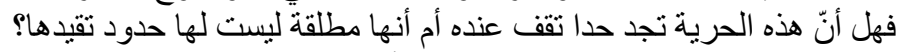

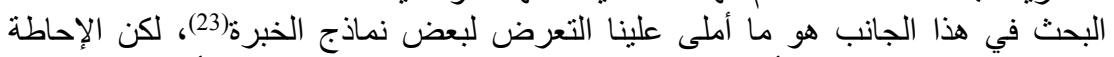

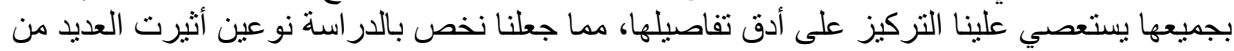

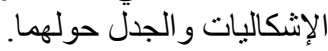
و عليه سنتناول في مرحلة أولى سلطة القاضي الجنائي في تقدير الخبرة المتعلقة بالإجهاض،

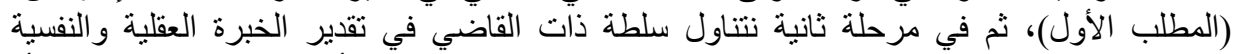

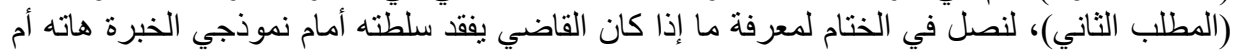

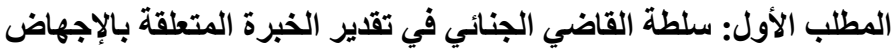

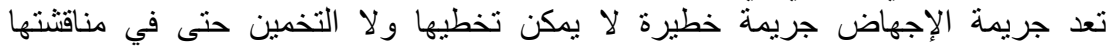

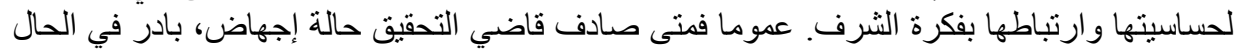

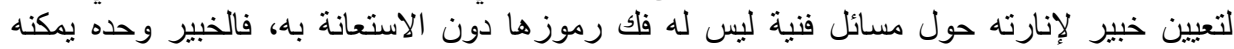

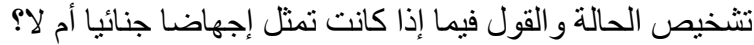

الفرع الأول: الإجهاض وأنواعه الإنه

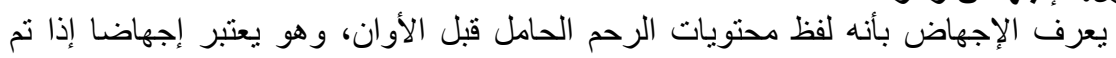

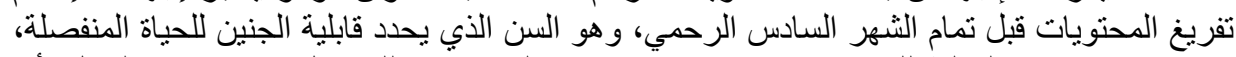

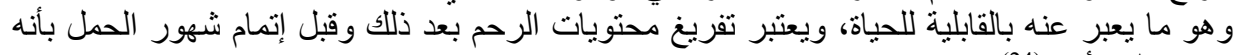

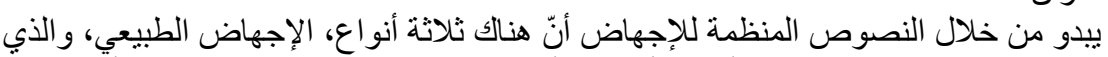
و لادة قبل الأوان (24).

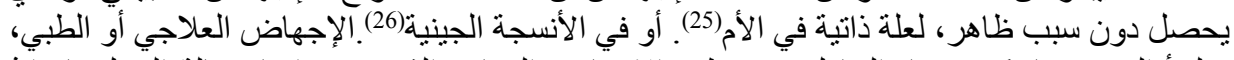

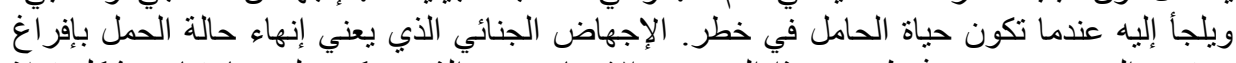

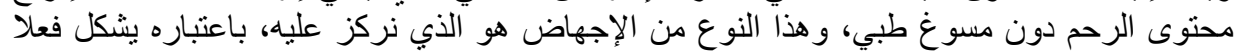

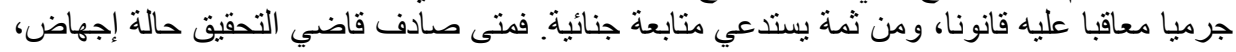

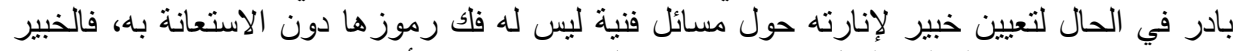

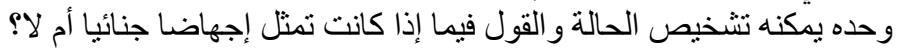

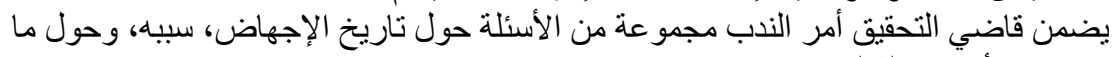

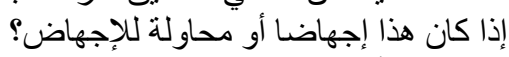

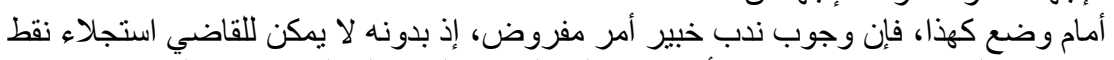

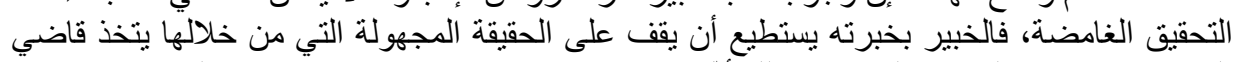

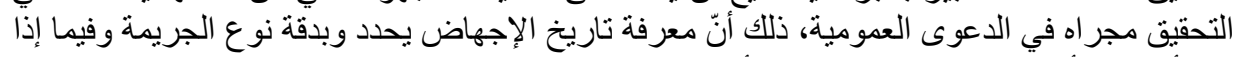

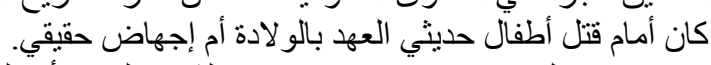

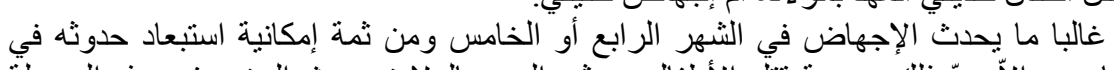

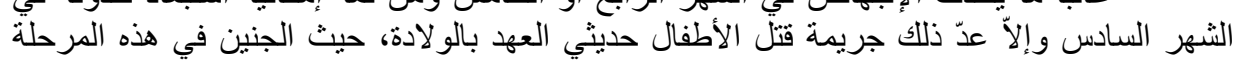

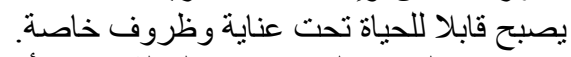

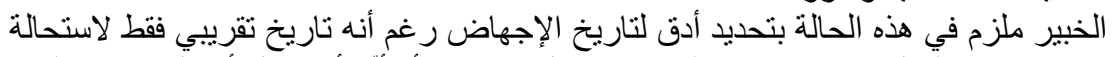

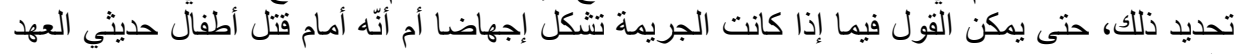

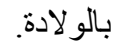

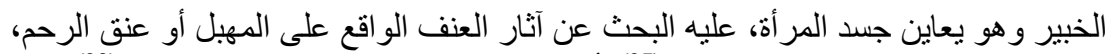

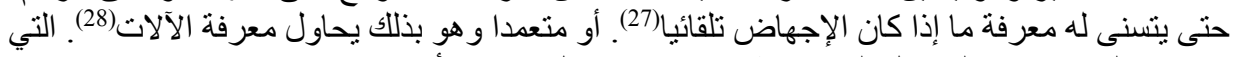
تم استعمالها حتى ينم التوصل إلى معر فة ما إذا كانت بفعل مختص أو شخص عادي؟ 
منى كان الإجهاض جنائيا وليس طبيعيا، فعلى الخبير تحديد ما إذا كان إجهاضـا أو أنّه مجرد

ولكن ألا ينطوي هذا على نوع من التعارض؟ كون المسألة قانونية وتدخل في صميم

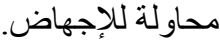

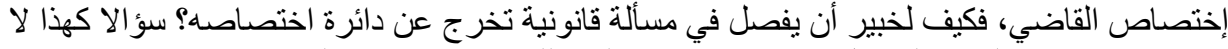

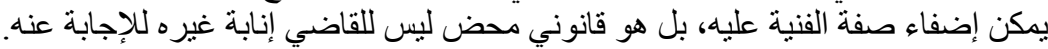
الفرع الثاني: القيمة الإقناعية للخبرة

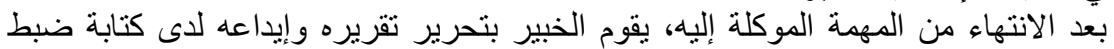

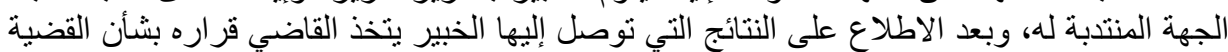

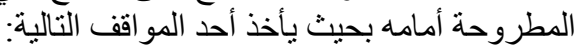

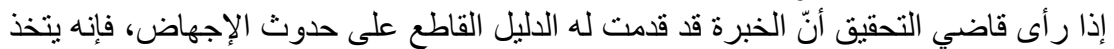

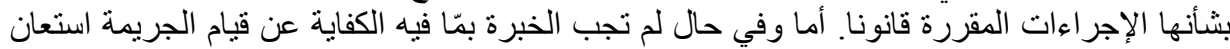

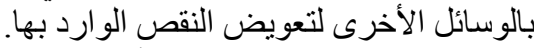
إذا كثفت الخبرة عن أنّ سبب الإجهاض كان علاجي أو طبيعي فإنه بصدر أمر ا بألا وجه

من المقرر أنّ تقدير أراء الخبراء مرجعه للقاضي الذي له كامل الحرية في تقدير القوة التنليلية لتقرير

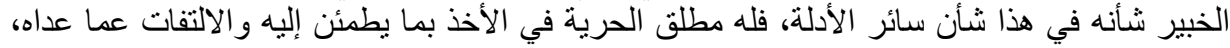

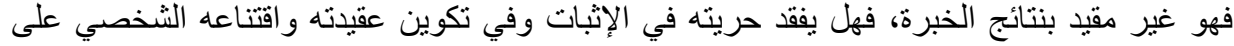
إذا كان الأصل هو حرية القاضي الجنائي في تقدير تقرير الخبرة، وعدم تقيبيده في أي حالة جريمة الإجهاض هذه الإن

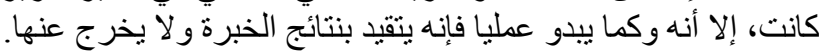

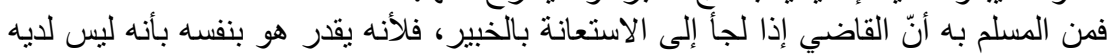

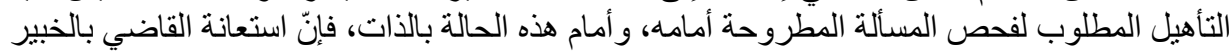

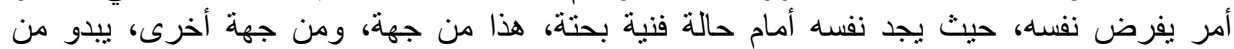

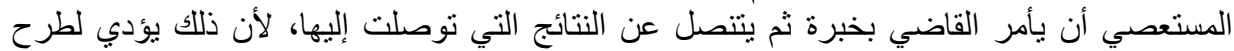

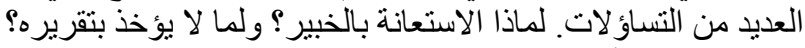

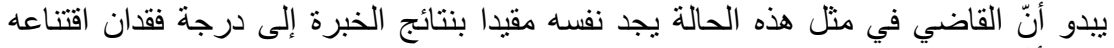

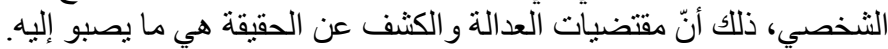

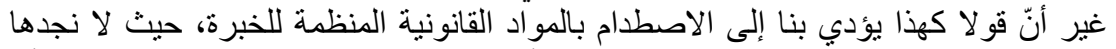

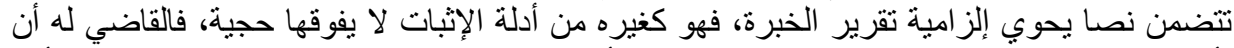

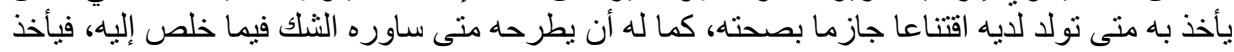

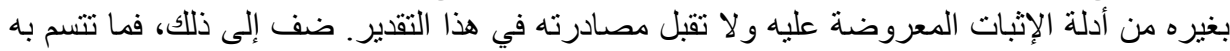

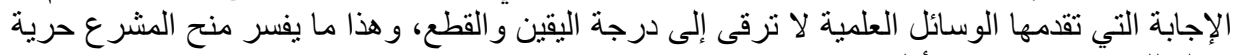
كاملة للقاضي في تقدير الأدلة. ولكن ماذا لو ناقضت شهادة شاهد أو إعتراف منهم ما أفرزه نقرير الخبرة؟ فبائهم يأخذ

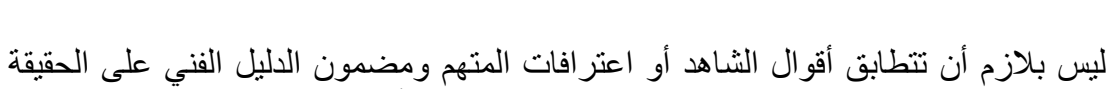

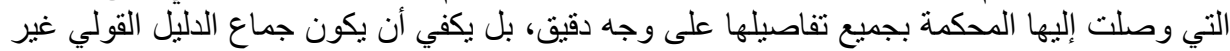

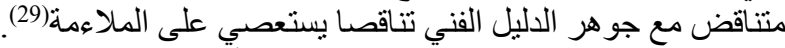

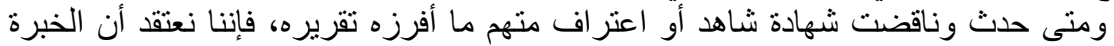

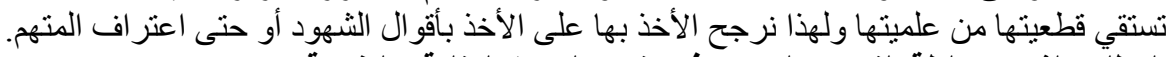
المطلب الثاني: سلطة القاضي الجنائي في تقدير الخبرة العقلية و النفسية 
بعدما تطرقنا إلى سلطة القاضي الجنائي في تقدير الخبرة المتعلقة بالإجهاض، نتطرق إلى الى إلى

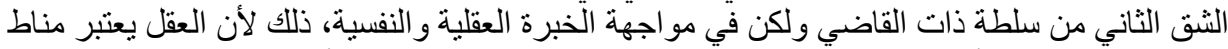

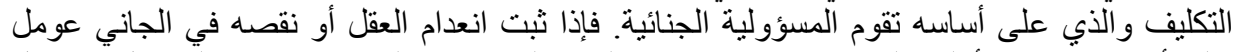

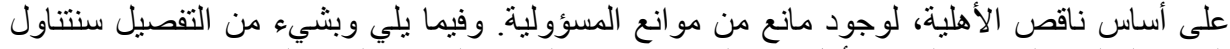

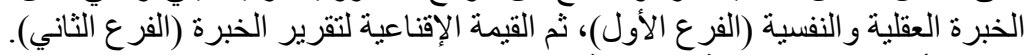
الفرع الأول: الخبرة العقلية والنفسية النية

إنّ الإتيان على جريمة ماديا لإيلى لا يؤدي حتما إلى تطبيق العقوبة المقررة قانونا لمرتكبها، فلا يعاقب هذا الأخير إلا إذا أنثبت القاضي مسؤوليته الجنائية.

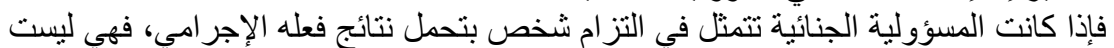

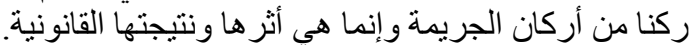

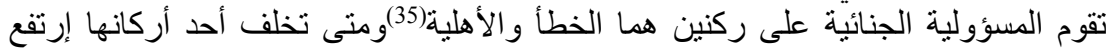

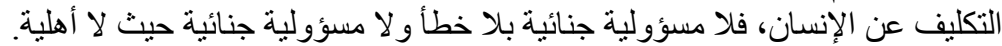

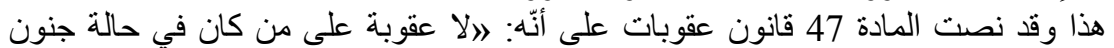

تثير هذه المادة بعض الصعوبات، فهي لم تضع تعريفا للجنونكما لم تنشر إلى عاهات العقل العاتل

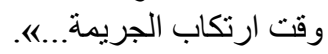

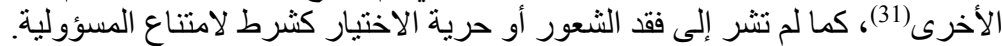

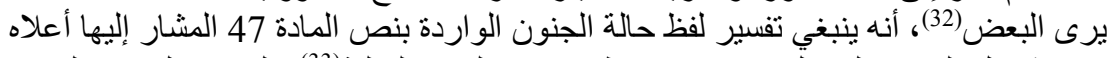

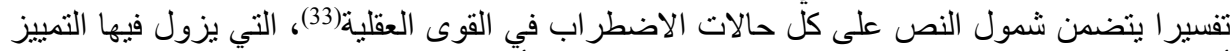

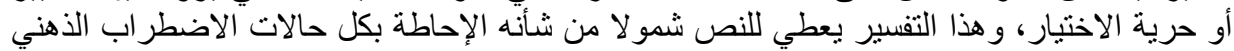

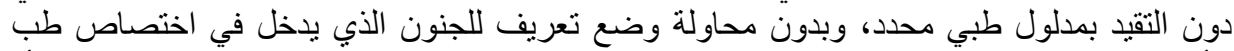

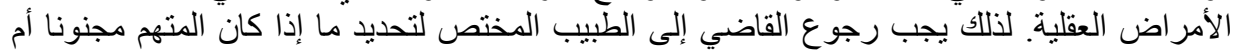

رغم إبقاء المادة سالفة الذكر على الوصف الجرمي للفعل المرتكب، إلا أنها لم ترتب أية

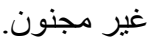
عقوبة لانتفاء إمكانية إسناد الفعل معنويا.

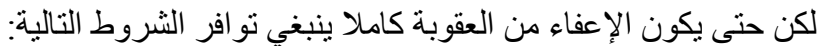

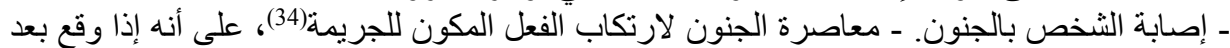

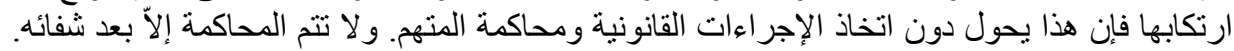

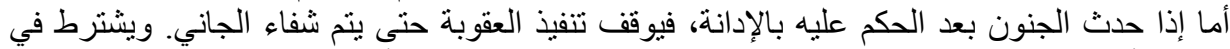

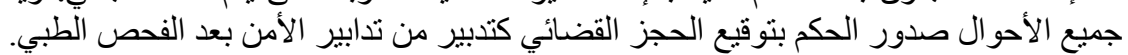

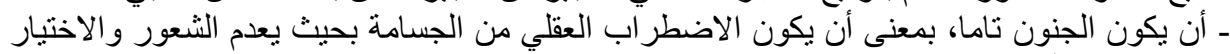

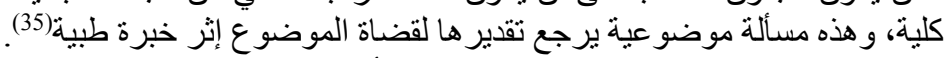

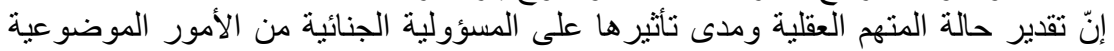

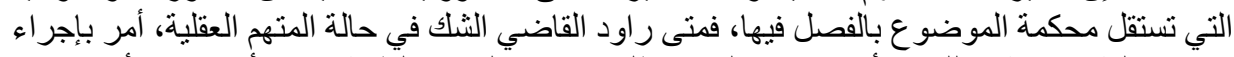

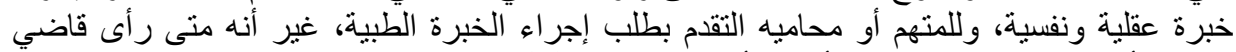

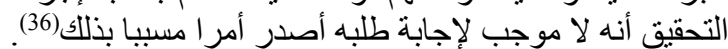

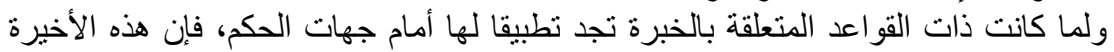

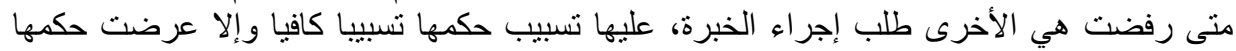

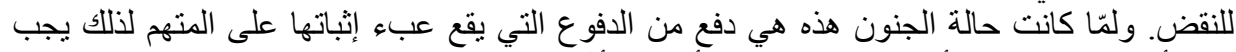

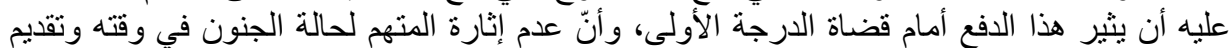

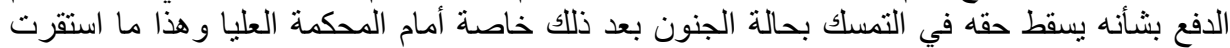
عليه هذه الأخيرة حين قررت أنهّلا يجوز للطاعن أن يتمسك بهذا الدفع للمرة الأولى أمام المحكمة العليا 
منى ثبت من التحقيقات التي أجريت في الدعوى ومن محضر المر افعات أنّ المتهم لم يكن مصابا بأي لمأي

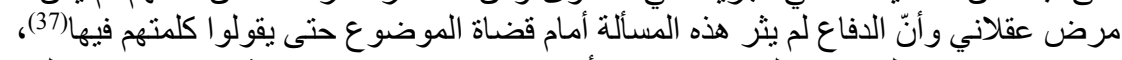

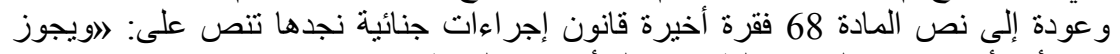

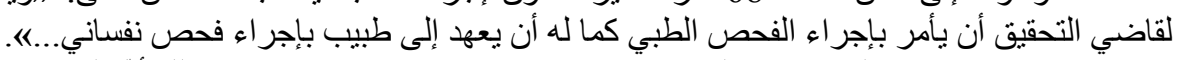

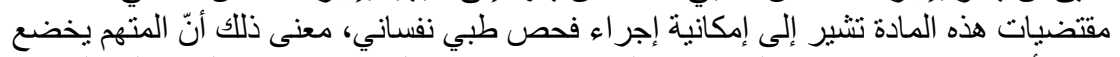

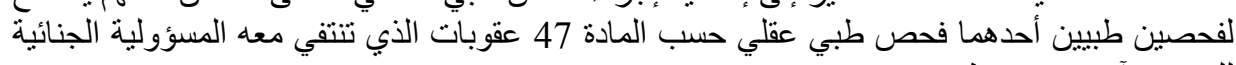
للمتهم، وآخر فحص طبين أحدبي نفسي.

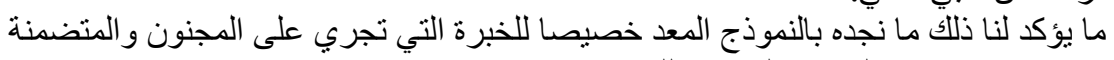

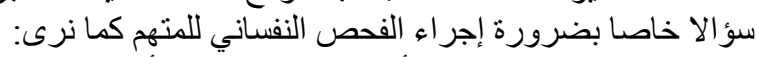

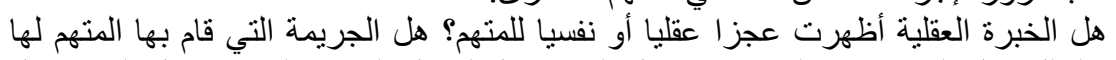

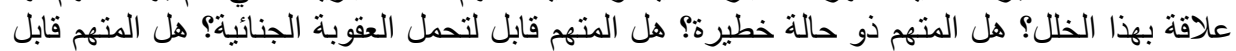

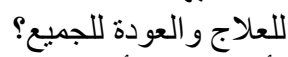

نأمر الخبير أن يقدم تقرير الجمهي مفصلا بعد إعطاء رأيه المبرر وأن بلاحظ في تقريره بأنه قام شخصيا

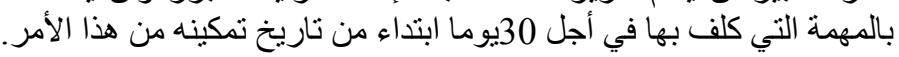

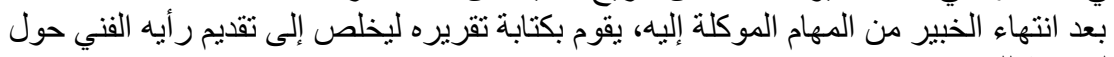

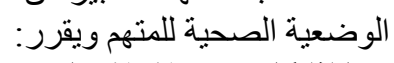

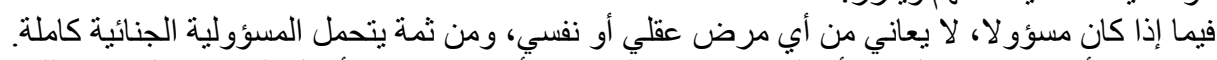

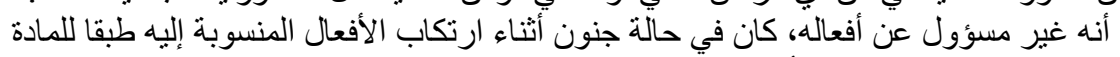

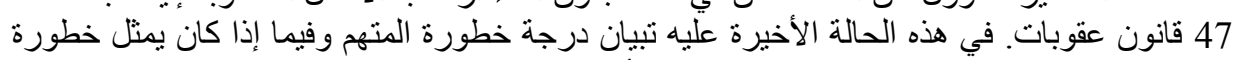

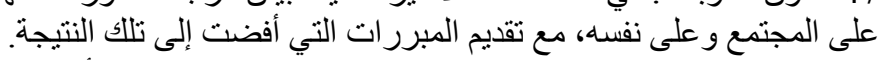

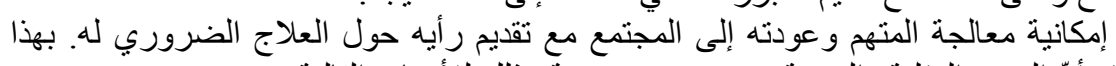

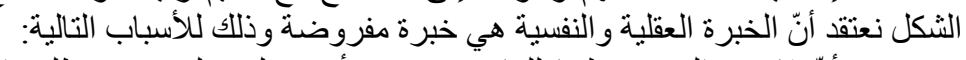

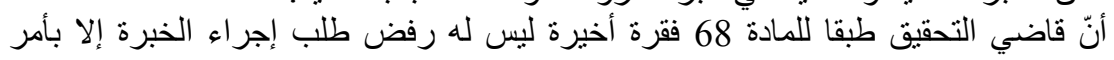

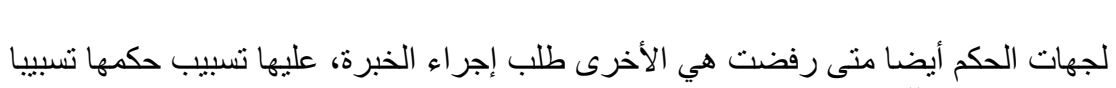
كافيا و إلا عرضت حكمها للنقض. الحكر ضرورة إجراء تحقيق حول شخصية المنهم حسب ما هو وارئ وارد بالمادة 68 فقرة 8 وكذللك

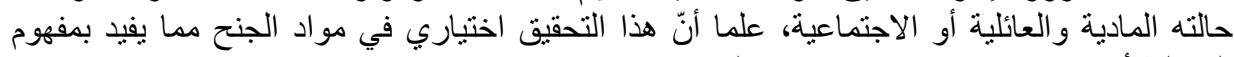

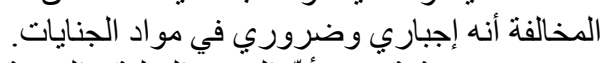

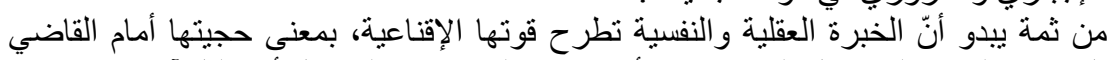

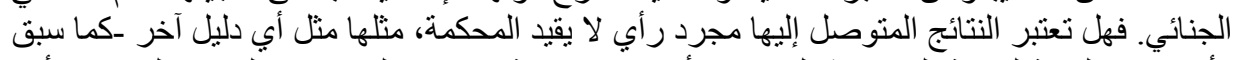

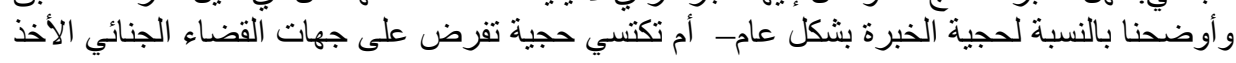

الفرع الثاني: القيمة الإقناعية لتقرير الخبرة

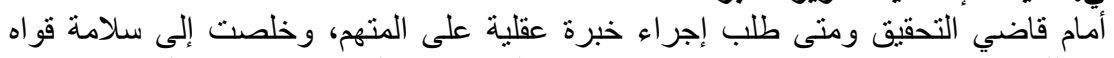

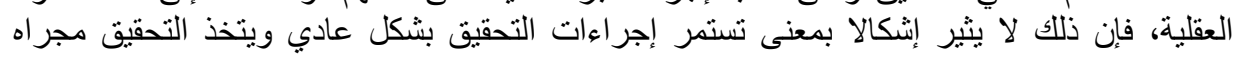

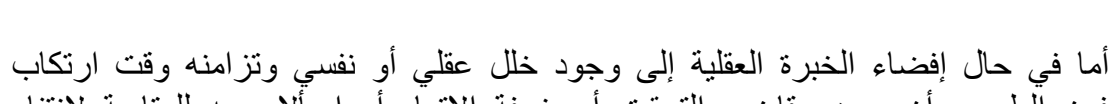
الطبيعي.

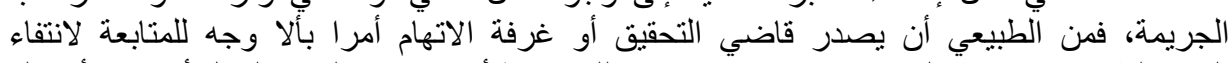

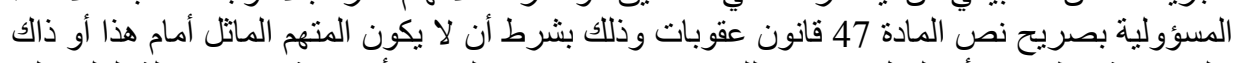

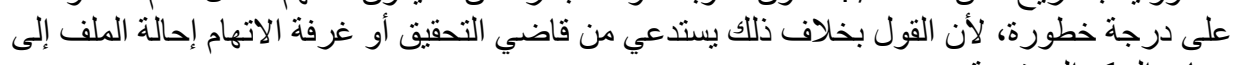
جهات الحكم المختصة. 
أما قاضي الحكم، ولما كان إثبات صحة قوى المتهم من عدمه يرجع إلى تقرير الخبير، فما

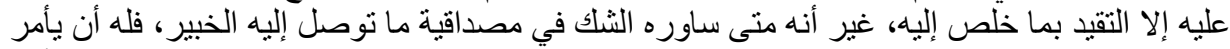

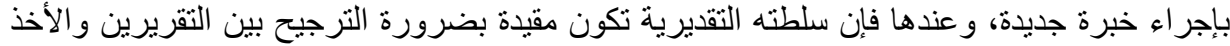

فئنى ثبتت عدم مسؤولية المتهم فعليه أن يقضي ببر اءته من العقوبة وتقرير التدبير (38)الملائم

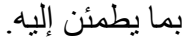

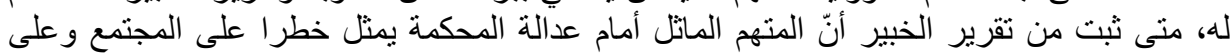

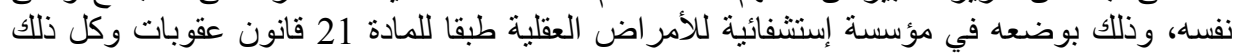

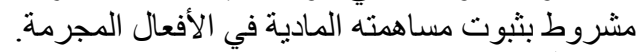

الخاتمة

إنّ الخبرة كدليل فني تلعب دورا هاما في تكوين عقيدة القاضي الوجدانية للوصول إلى الحقيقة

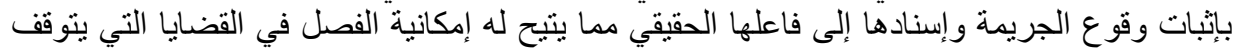

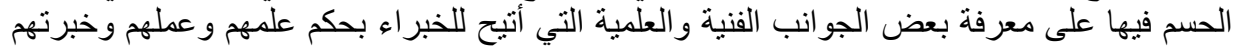

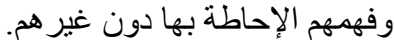

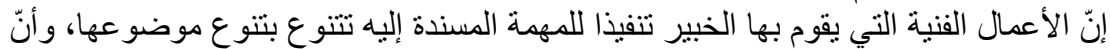

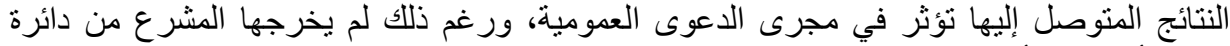

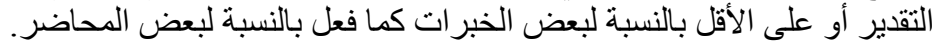

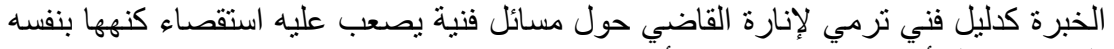

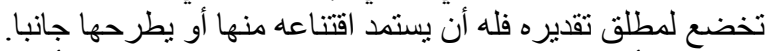

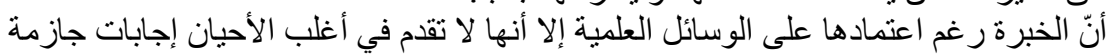

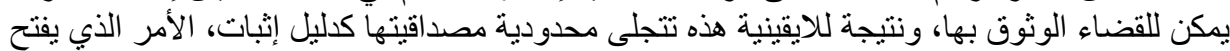

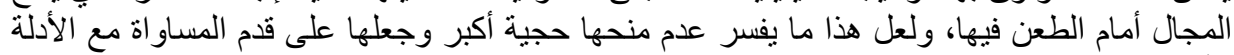

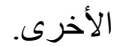

تباعا لما تم التوصل إليه من نتائج فإننا نقتر ح جملة من الاقتر احات نوجز ها على القي النحو التالي:

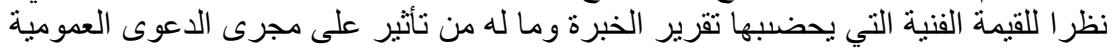

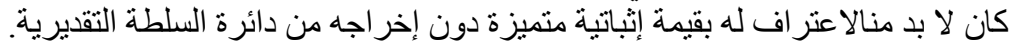
لا بد منالاستعانة بالخبراء في المسائل الفنية البحتة لتحري العدة العدالة وسلامة التقدير الفني

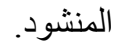

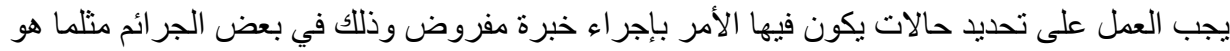

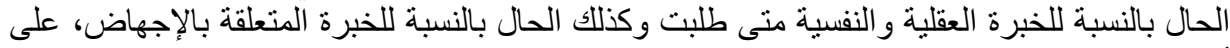
أن بعتمد هذا على معايير موضو عية تخدم مصلحة العدالة بصفة عامة.

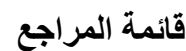
1 الذنيبات غازي مبـارك، الخبرة الفنية في إثبات الثزوير في المستندات الخطية فنا وقانونا، عمان، دار

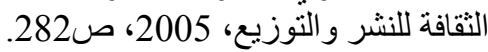
2 عـوض محسـي الدين، قانون الإجراءات الجنائية السوداني، القاهرة، مطبعة القاهرة و الكتاب الجامعي،

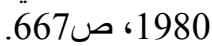

GARRAUD (R), Traite théorique et pratique d'instruction criminelle et de ${ }^{3}$ procédure, T.V, Paris, Sirey, 1929, p564. ARSICO (A), Lezioni di dirittoprocessualepenale, Napoli, Jovene, 1952, p185. ${ }^{4}$ 5 عثــان أمال عبد الرحيم، الخبرة في المسائل الجنائية، القاهرة، دار النهضة العربية، 1964، 
6 مـروان محســد، نظام الإثبات في المواد الجنائية في القانون الوضعي الجزائري، ج1، ج2،

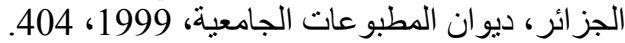

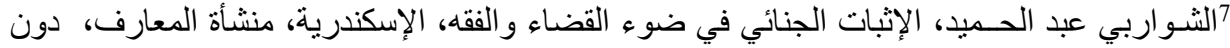

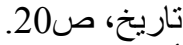

أبو عـامر محمد زكـي، الإثبات في المواد الجنائية، الإسكندرية، الفنية للطباعة والنشر، دون تاريخ،

عبد الستار فوزيـــة، شرح قانون أصول المحاكمات الجزائية اللبناني، بيروت، دار النهضة

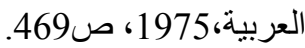

حسنـي محمود نجيب، شرح قانون الإجراءات الجنائية، ط2، القاهرة، دار النهضة العربية، 1988، ص480

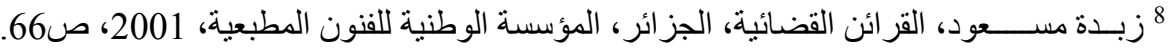

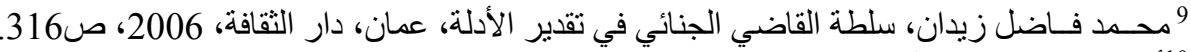

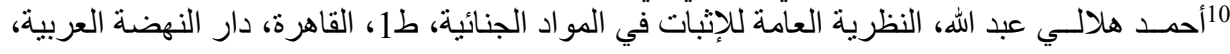

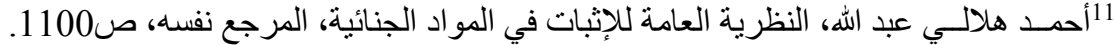

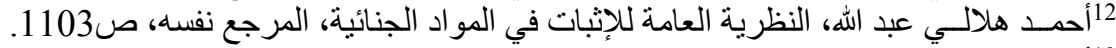

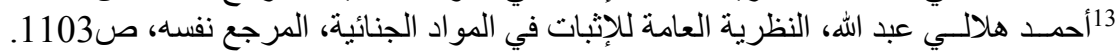

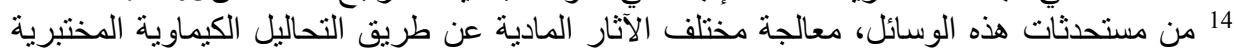

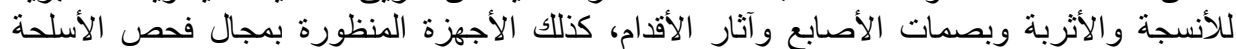

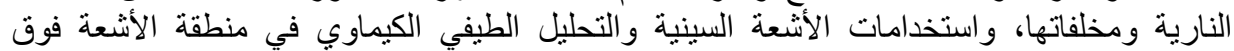

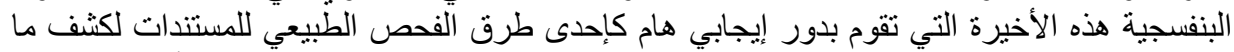
تتضمنه من آثار التزوير، وكذللك الكثف عن الكتابات السرية لإظهار البصمات على أسطح متعددة.

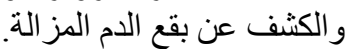

للأشعة الحمر اءدور أيضا في مجال الإثبات فهي تستخدم للبحث عن آثار البارود في حوادث الأسلحة

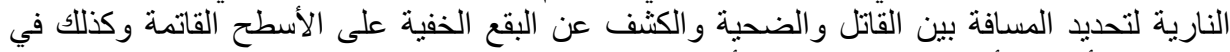

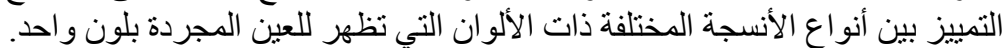

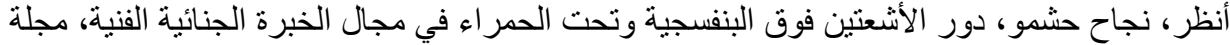

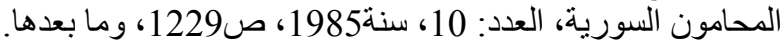

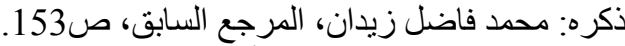

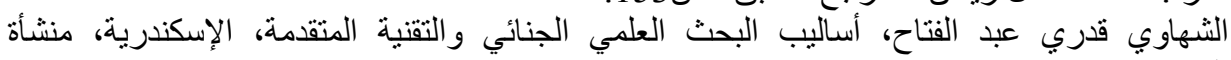

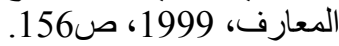
15 أنثار المشرع الجز ائري إلى هذه المحاضر بمقتضى المادة 216 من ق.إ.ج قائلا "في الأحوال التي

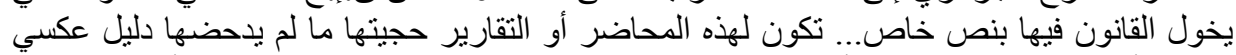

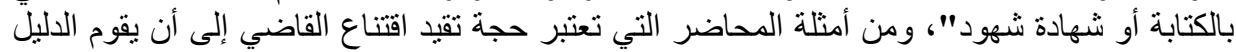

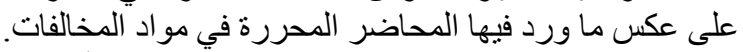

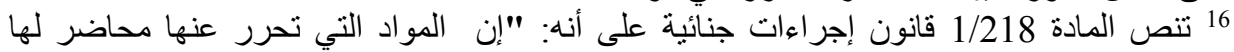

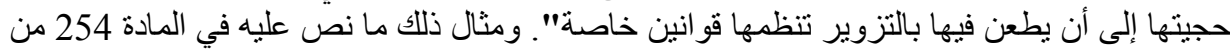

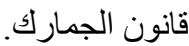

17 الدحكمة العليا، القسم الثاني للغرفة الجنائية الثانية، قرار بتاريخ: 22 جانفي 1981، رقانئ رقم: 22.641.

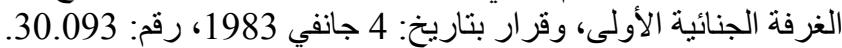

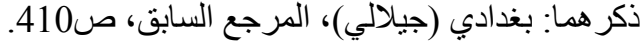




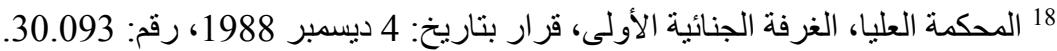

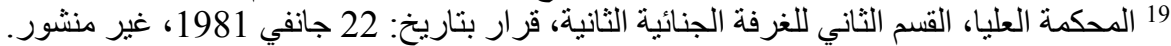

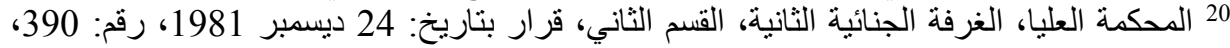

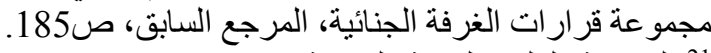

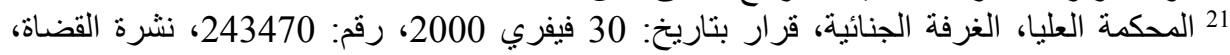

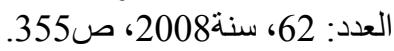

22 أحمـــ إبراهيم سيـد، الخبرة في المواد الددنية والجنائية فقها وقضاء، مصر، دار الكتب

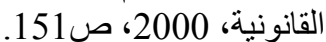

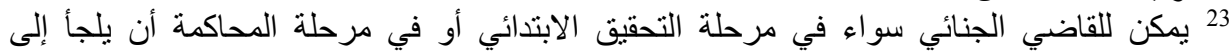

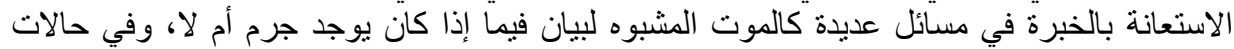

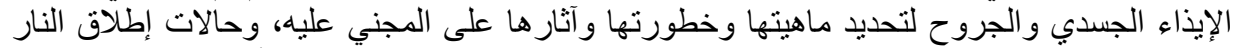

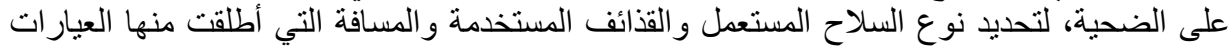
النارية، ولمعرفة مسار المقذوف لربط ذللك كله بالجريمة، لتحديد أسباب الوفاة، وفي حالات الإيذاء الإياء

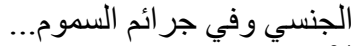

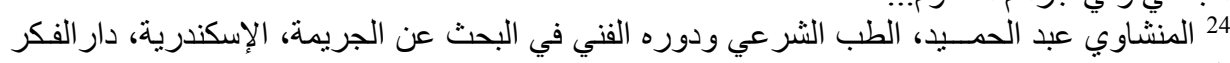

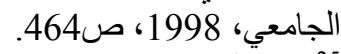

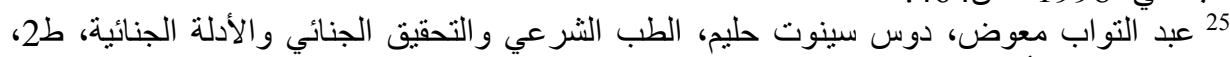

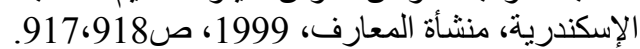

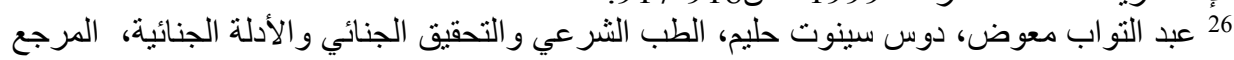

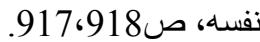
27 وهو شائع الحصول، ترجع أسبابه إلى إصابة الأم بأمراض أهمها: الزهري، الالتهاب الرئوي، الإنيا

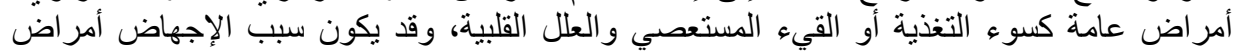
خاصة بأنسجة البويضة أو الأنسجة الجنينية.

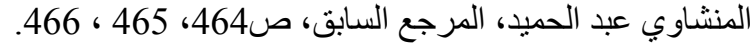

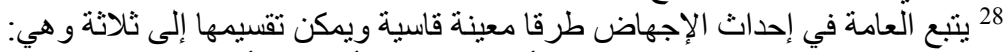

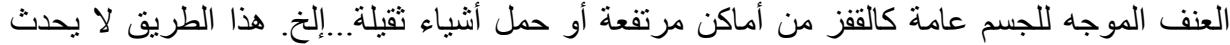

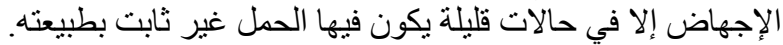
العنف الواقع موضعيا على أعضاء التناسل كإدخال مو اد سامة داخل المهيل فئل مثل الزرنيخ لإحداث تهيج

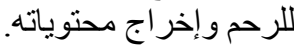

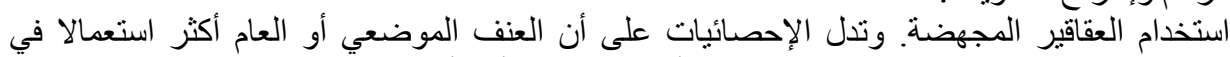

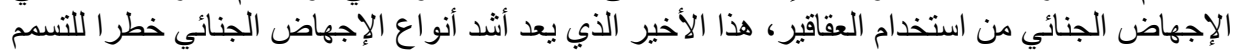

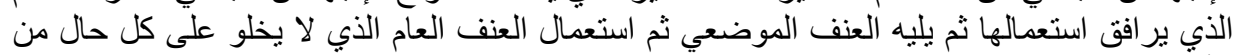

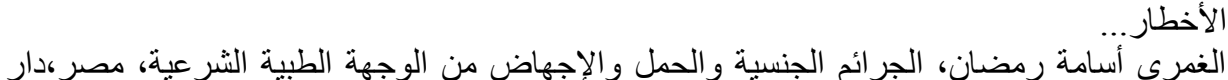

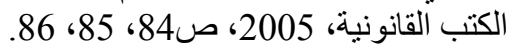
29 عبد التو اب معوض، دوس سينوت حليم، الطب الثر عي والتحقيق الجنائي و الأدلة الجنائية، المرجع

30بوسقيعـة أحســن، الوجيز في القانون الجزائي العام، ط3، الجزائر، دار هومة، 2006، ص192. 
31 نص القانون المصري بموجب المادة 62 عقوبات على الجنون و عاهة العقل، وبهذا شمل كل حالات اضطر اب القوى التي يزول فيها الاختيار أو الإدر الك.

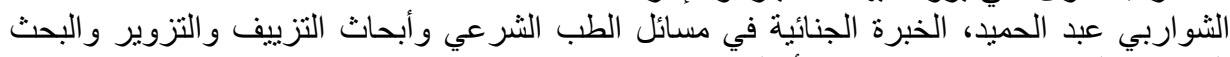

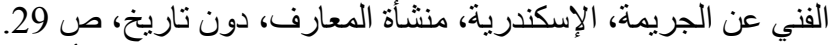

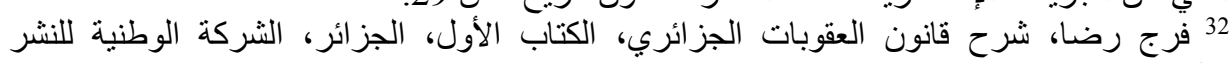

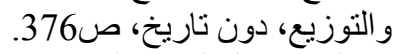

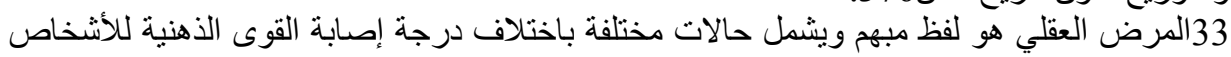

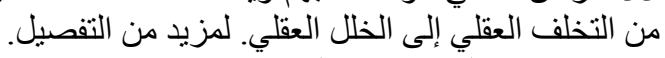

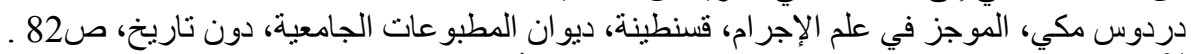

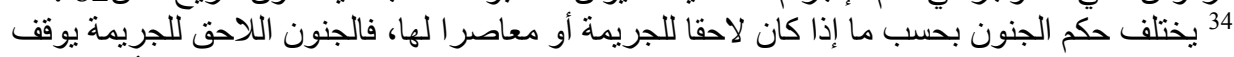

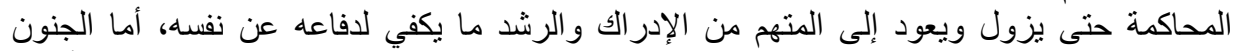

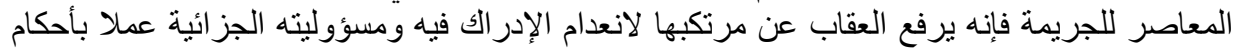

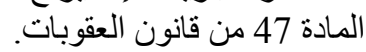
المحكمة العلبا، الغرفة الجنائية الأولى، قرار بتاريخ العاريخ: 10 مارس 1981، رقم: 21200.

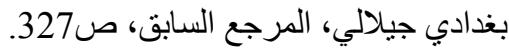
الا يجوز إعفاء المتهم بسبب الجنون إلا استنادا إلى تقرير خبير.

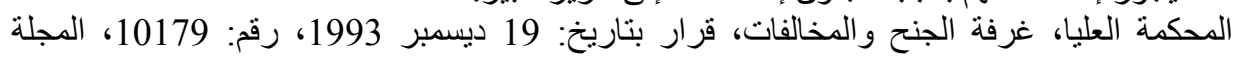

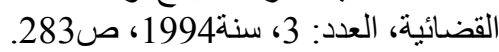

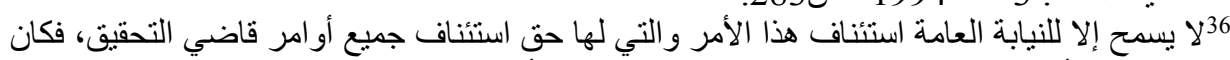

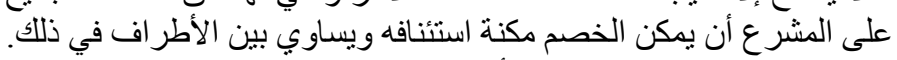

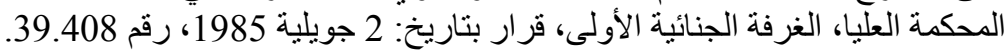

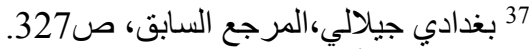

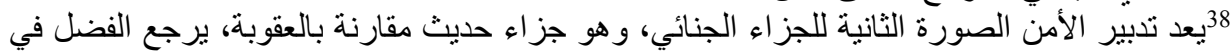

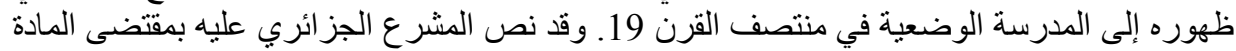

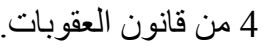

